\title{
Identifying sources of adolescent exclusion due to violence: Participatory mapping in South Africa
}

Nora Kenworthy

Kelly Hallman

Population Council

Judith A. Diers

Population Council

Follow this and additional works at: https://knowledgecommons.popcouncil.org/departments_sbsr-pgy

Part of the Demography, Population, and Ecology Commons, Family, Life Course, and Society Commons, Gender and Sexuality Commons, and the International Public Health Commons How does access to this work benefit you? Let us know!

\section{Recommended Citation}

Kenworthy, Nora, Kelly Hallman, and Judith A. Diers. 2008. "Identifying sources of adolescent exclusion due to violence: Participatory mapping in South Africa," Promoting Healthy, Safe, and Productive Transitions to Adulthood Brief no. 30. New York: Population Council. 


\section{Identifying sources of adolescent exclusion due to violence: Participatory mapping in South Africa}

\section{Prepared by Nora Kenworthy, Kelly Hallman, and Judith Diers}

A $s$ the first generation to grow up under democracy, adolescents in post-apartheid South Africa lead lives that are filled with new opportunities and overshadowed by rampant violence and crime. Even as the end of apartheid improved the lives of many South Africans and extinguished much of the political violence that preceded the transition, violent crime has increased dramatically within certain communities (Naude et al. 2006). The presence of multiple and simultaneous forms of violence and the systemic lack of safety are experienced most acutely by adolescents-in particular, adolescent girls (Brady 2002). High levels of violence and crime within the community are coupled with violence within the home and in schools: again, both of these phenomena primarily affect girls (HRW 2001; Wood and Jewkes 1998; Panos 2003).

The Population Council's Transitions to Adulthood program examines the particular factors that shape adolescents' life chances and choices. In South Africa, for instance, Council researchers have studied how economic literacy and life skills education affect young men and women who are economically and socially disenfranchised and at high risk for HIV infection (Hallman 2005). To take full advantage of the skills these programs promote, however, young people must have access to safe spaces-both within the program and beyond: in the home, at school, and in the community.

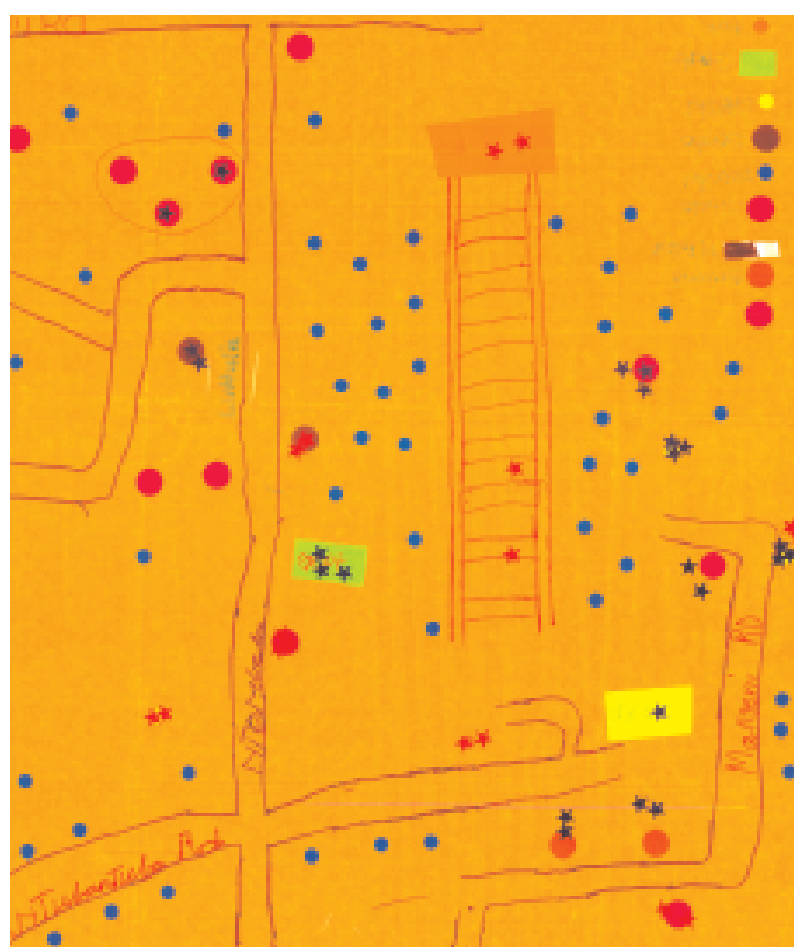

The Population Council collaborated with South Africa's Department of Education, UNICEF, and the Crime Reduction in Schools Project (CRISP) to investigate gender-based violence in KwaZulu-Natal. Participants mapped their neighborhoods, pinpointing safe and unsafe areas. None of the girls aged 10-13 could identify a community space in which they felt better than "somewhat safe." This exercise has helped neighborhood groups begin discussions with police and schools on ways to improve safety. 


\section{Creating safe spaces for adolescents}

In this context, "safe spaces" means not only physical areas where young men and women are safe from bodily harm, but also spaces where they feel emotionally secure and supported, are treated with respect, have access to social networks of peers and adult mentors, feel free to try new endeavors and express opinions, and move freely within their communities. Adolescence is typically a time when young adults expand their geographic and intellectual horizons; however, in South Africa-and for girls especially_it has become a time when their access to social networks and to the community and its resources narrows considerably.

Extensive research has been conducted on patterns of violence against adolescents. With the 2001 release of a Human Rights Watch report on sexual violence against girls in South African schools, school-based sexual violence became a major area of research in the developing world (HRW 2001). Subsequent studies often focused on girls as victims and boys and men as perpetrators, ignoring more widespread patterns of sexual violence against girls and boys beyond school grounds (Panos 2003; "Unsafe schools" 2003). By contrast, studies of violence against adolescents in developed countries have often focused on bullying, as well as inner-city gang-related violence and crime. Research on the wider patterns of violence against adolescents in South Africa is lacking, and studies should be undertaken to compare the three phenomena-community-, familial-, and school-based violence-side-by-side from the perspective of adolescents. Similarly, research on gender-based and school-based violence often either excludes boys or fails to provide direct comparisons between boys' and girls' experiences.

In addition to expanding adolescent research, the Council's work uses the Transitions to Adulthood framework to examine how these experiences change for young people at different stages of the transition. Researchers often fail to take into account that adolescence in many societies traditionally begins at a very younger age, thereby making younger populations (10-14 years) more vulnerable to violence (Population Council 2006). In South Africa in particular, young adolescents have experienced much higher rates of rape and sexual assault than peers in other countries, in part because of long-standing social hierarchies and misconceptions about possible cures for AIDS (Petersen et al. 2005). In order to create targeted age- and gender-appropriate interventions, studies of violence must examine how perceptions of safety differ for boys and girls as well as for younger and older age groups.

Using participatory mapping of communities to understand adolescent experiences

Mapping projects are a particularly effective method for engaging young people in participatory research, as well as portraying adolescents' perspectives through a socially and politically compelling medium (Population Council 2005; Austrian and Sakwa 2006). To measure the effects of personal insecurity on the daily lives of young men and women, the Council and the Crime Reduction in Schools Project (CRISP) conducted focus group workshops with youth in two communities outside of Durban: KwaMashu, which is urban, and Inanda, which is peri-urban. Youth in each community were asked to draw a map indicating safe and unsafe places in their neighborhoods.

Students from four participating schools were divided into four demographic groups: 10-13-year-old girls (grade 5), 10-13-year-old boys (grade 5), 14-16-year-old girls (grade 8), and 14-16-year-old boys (grade 8). Members of each group were asked to identify and map important spaces in their communities and then rate these spaces in terms of their safety, using colored stars: three red stars for very unsafe, two for mostly unsafe, one for somewhat unsafe; one blue star for somewhat safe, two for mostly safe, and three for very safe. The participants were encouraged to explain why they perceived each space to be safe or unsafe, and discuss how they coped with the lack of safety in various places. Focus groups of adult men and women from the school community were also convened when possible as a means for comparing the perceptions of adolescents with those of adults. All participants were asked to discuss potential solutions and to identify local and regional actors who should be involved in remedying the situation.

\section{Adolescents' perceptions of safe and unsafe spaces}

Because adolescence is a period of rapid transition between childhood and adulthood-and one that differs widely by gender-it is hardly surprising that the maps created by each group revealed stark differences in the 
ways that younger and older adolescents, and boys and girls, interact with their communities. All of the participants identified many spaces within their surroundingsschools, clinics, libraries, neighborhoods-to which young people ostensibly should have safe access but in these communities do not. However, reasons for a perceived lack of safety differed strikingly between boys and girls: girls identified far more physical dangers, many of them associated with the risk of sexual assault and rape. Young girls (ages 10-13) are the most vulnerable-in neither of the settings could girls in this age group identify a single place in their communities that they recognized as more than "somewhat safe." By contrast, boys recognized insecure places-buildings and areas prone to burglaryand spaces with physical hazards. These findings are corroborated by the work of Mitchell et al., who used photography to assist schoolchildren in identifying unsafe places in their environment (Mitchell et al. 2005). As boys grew older, their spheres of access to the community and its resources expanded, whereas girls' areas of access contracted considerably. Every group, however, constructed diagrammatic evidence of widespread adolescent victimization in multiple spaces within the communities, showing that young people of both sexes are bearing the brunt of the violence in South Africa.

\section{Addressing the need for safe spaces}

The school setting itself proved to be a challenging environment in which to conduct research, because time for focus groups was severely limited and school schedules did not allow for adequate follow-up or in-depth discussion. Despite this challenge, the results provide compelling new evidence of how adolescents are experiencing violence and how their needs for safe spaces can be addressed. The following findings merit close attention:

- Everyone in the community experiences violence to some extent, but adolescents are more apt to perceive and experience a greater degree of violence than their adult counterparts. Male and female adolescents in both age groups experience different sources of safety and violence within the community, and are often unaware of the threats faced by the opposite sex.

- Younger age groups are more vulnerable to violence, and younger girls in particular are deeply affected by the lack of safety in communities.
- The majority of schools were rated as unsafe in both peri-urban and urban areas.

- Sexual assault and rape are especially prevalent; girls are the primary targets of such abuse; and few services exist to protect girls from assault or to assist them afterward.

- Although adolescents and the community at large often knew the perpetrators of violence-especially sexual violence-they were reluctant or felt unable to respond to such acts or to report suspected perpetrators.

- For girls, insecurity pervades social networks, often restricting access to social services and community activities. Yet, even as their freedom to move about within the community becomes more restricted because of the threat of violence, young women continue to face daily situations-at school, at home, while walking, and while performing necessary domestic tasks-in which they feel unsafe and are at risk of bodily and psychological harm.

Social service sites such as health clinics and welfare offices were perceived as unsafe when services were not adequately provided or if the population in question was excluded from such services. This points to the larger experiences and awareness of structural violence in adolescent lives. The "violence of everyday life" that often occurs in the form of institutional and governmental neglect not only deprives young people of basic rights, but also fuels further cycles of violence and crime within communities (Kleinman 1997).

\section{Allowing adolescents to influence community-based solutions}

The mapping project allowed young adults to formulate perceptions of their community within a protected environment, while at the same time empowering them to devise their own solutions to the safety problems they uncovered as a group. Thus, the project comprised both the mapping activity itself and opportunities for the youth involved to present and disseminate the findings to community stakeholders and authorities in order to influence future planning and policymaking. These findings have also informed the way in which the Population Council shapes its approaches to creating and maintaining safe spaces for youth, and how these interventions must be tailored to suit the different experiences of boys and girls and older and younger populations. 


\section{Translating adolescent knowledge into improved} livelihoods: The way forward

The mapping initiative opens a door to both grassroots interventions and further research. The project proved to be an effective and low-cost participatory method for identifying unsafe spaces, discussing and evaluating current coping mechanisms, and proposing potential community interventions. As such, it could easily be replicated as an intervention or as part of larger crime- and violence-reduction strategies. Furthermore, given the widespread prevalence of perceptions among adolescents that safety is lacking in communities, more research into how this affects adolescent subpopulations and their development is certainly needed. It is essential to continue looking at how the age of adolescents and their place within communities may fuel their vulnerability, and how more positive adult-child or peer relationships might offer increased safety. Most importantly, additional spaces and new forms of protection must be provided to adolescents-not only to provide safe spaces per se, but also to make up for the deficits in social assets and services caused by such high levels of community insecurity.

\section{References and related publications}

Austrian, Karen and Caroline Sakwa. 2006. "Defining girls' unmet need for safety." Presentation, The Binti Pamoja Center, Nairobi, Kenya.

Brady, Martha. 2002. "Safe spaces for girls," In Charting Directions for a Second Generation of Programming, UNFPA Workshop Background Document, 1-3 May. New York: Population Council.

Hallman, Kelly. 2005. "Gendered socioeconomic conditions and HIV risk behaviours among young people in South Africa," African Journal of AIDS Research 4(1): 37-50.

Human Rights Watch (HRW). 2001. "Scared at school: Sexual violence against girls in South African schools." http://www.hrw.org/reports/2001/safrica.

Klienman, Arthur. 1997. "The violences of everyday life: The multiple forms and dynamics of social violence," in Veena Das, Arthur Kleinman, Mamphela Ramphele, and Pamela Reynolds, eds., Violence and Subjectivity. Berkeley: University of California Press.
Leoschut, Lezanne and Patrick Burton. 2006. "How rich the rewards? Results of the 2005 National Youth Victimisation Study." Monograph Series, No 1. Cape Town: Centre for Justice and Crime Prevention.

Mitchell, C., et al. 2005. "Taking pictures, taking action! Using photo-voice techniques with children," ChildrenFIRST 9:(60):27-31.

Panos Institute. 2003. Beyond Victims and Villains: Addressing Sexual Violence in the Education Sector. London: Panos Institute.

Petersen, Inge, Arvin Bhana, and Mary McKay. 2005. "Sexual violence and youth in South Africa: The need for community-based prevention interventions," Child Abuse and Neglect 29, 1233-1248.

Population Council. 2006. "Investing when it counts: Generating the evidence base for policies and programmes for very young adolescents." New York: UNFPA and Population Council.

Population Council and Crime Reduction in Schools Project. 2005. "Guidance for mapping safer schools and communities." Donor report to UNICEF, South Africa. New York: Population Council.

"Unsafe schools: A literature review of school-related genderbased violence in developing countries." 2003. Washington, DC: USAID / Wellesley Centers for Women and DTS.

Wood, Katharine and Rachel Jewkes. 1998. "Love is a dangerous thing': Micro-dynamics of violence in sexual relationships of young people in Umtata." Pretoria, South Africa: Medical Research Council.

\section{Donors}

Department for International Development (DFID);

United Nations Children's Fund (UNICEF)

Partner institutions

Crime Reduction in Schools Project (CRISP)

Research collaborators

Nick Swan

For more information or for copies of other briefs, contact publications@popcouncil.org For additional resources see www.popcouncil.org/pgy

Population Council

One Dag Hammarskjold Plaza

New York, New York 10017 USA

(C) 2008 by The Population Council, Inc. 